\title{
LA DISCIPLINA DE LA PROTECCIÓN DEL PAISAJE EN LA COMUNIDAD AUTÓNOMA DE GALICIA ${ }^{(.)}$
}

\author{
Marcos Almeida CERREDA \\ Profesor contratado doctor \\ Universidad de Santiago de Compostela \\ marcos.almeida@usc.es \\ DiANA SANTIAGO IGLESIAS \\ Profesora ayudante doctor \\ Universidad de Santiago de Compostela \\ diana.santiago@usc.es
}

Recibido: 27 de abril de 2010 / Aceptado: 10 de mayo de 2010

RESUMEN: Los poderes públicos se han ido concienciando de la importancia del paisaje como recurso económico y como elemento integrante de la cultura propia de Galicia. Esta sensibilización se ha traducido en la aprobación de la Ley 7/2008, de 7 de julio, de Protección del Paisaje de Galicia, analizada en este trabajo.

RESUM: Els poders públics s'han anat conscienciant de la importància del paisatge com a recurs econòmic i com a element integrant de la cultura pròpia de Galícia.

\footnotetext{
(.) En el presente trabajo se han empleado las siguientes abreviaturas: BOPG, Boletín Oficial del Parlamento de Galicia; CEP, Convenio Europeo del Paisaje; confere, cfr.; GPPG, Grupo del Partido Popular de Galicia; LCPGOP, Ley 8/2005, de 8 de junio, de Protección, Gestión y Ordenación del Paisaje de Cataluña; LPPG, Ley 7/2008, de 7 de julio, de protección del paisaje de Galicia; LVOTPP, Ley 4/2004, de 30 de junio, de Ordenación del Territorio y Protección del Paisaje de Valencia; número, núm.; páginas, pp.; RPC, Decreto 343/2006, de 19 de septiembre, por el que se desarrolla la Ley 8/2005, de 8 de junio, de Protección, Gestión y Ordenación del Paisaje de Cataluña; RPCV, Decreto 120/2006, de 11 de agosto, por el que se aprueba el Reglamento de Paisaje de la Comunidad Valenciana; ss., siguientes; vid., videre.; vol., volumen.
} 
Aquesta sensibilització s'ha traduït en l'aprovació de la Lei 7/2008, do 7 de xullo, de protección da paisaxe de Galicia, analitzada en aquest treball.

\begin{abstract}
Public powers have been becoming aware of the importance of landscape as an economic resource and as element integrating the peculiar culture of Galicia. The awareness rising about this issue has culminated with the Lei 7/2008, do 7 de xullo, de protección da paisaxe de Galicia (Landscape Protection Act 2008), which is analyzed in this note.
\end{abstract}

PALABRAS CLAVE: Tutela y gestión del paisaje — Instrumentos de análisis, estudio y sensibilización en materia de paisaje

PARAULES CLAU: Tutela i gestió del paisatge — Instruments d'anàlisi, estudi i sensibilització en matèria de paisatge

KEYWORDS: Landscape protection and management - Means of analysis, study and awareness rising regarding landscape

SUMARIO: I. Introducción: la creciente relevancia jurídica del paisaje y su progresiva tutela en la comunidad autónoma gallega. II. La Ley 7/2008, de 7 de julio, de protección del paisaje de Galicia. 1. Marco competencial. 2. Objeto, fin y ámbito. 3. Principios rectores en materia de paisaje. 3.1. Principio de reconocimiento jurídico de la relevancia del paisaje. 3.2. Principio de ordenación, gestión y protección del paisaje. 3.3. Principio de promoción del paisaje. 3.4. Principio de colaboración interadministrativa y colaboración público-privada en la protección y fomento del paisaje. 4. Instrumentos jurídicos en materia de paisaje. 4.1. Instrumentos para la protección, gestión, ordenación y promoción del paisaje. A. Instrumentos imperativos unilaterales. A.1. Catálogos del paisaje. A.2. Directrices de paisaje. A.3. Estudios de impacto e integración paisajística. A.4. Planes de acción del paisaje en áreas protegidas. B. Instrumentos voluntarios bilaterales o multilaterales. B.1. Pactos por el paisaje. B.2. Acuerdos voluntarios en áreas de especial interés paisajístico. 4.2. Instrumentos de análisis, estudio y sensibilización en materia de paisaje. A. Observatorio gallego del paisaje. B. Acciones de formación, sensibilización, educación y concertación. III. Reflexiones finales. IV. Bibliografía. 


\section{INTRODUCCIÓN: LA CRECIENTE RELEVANCIA JURÍDICA DEL} PAISAJE Y SU PROGRESIVA TUTELA EN LA COMUNIDAD AUTÓNOMA

\section{GALLEGA}

La Comunidad Autónoma de Galicia posee una gran riqueza paisajística, integrada por un mosaico de muy diversos paisajes: litorales, fluviales, pétreos, boscosos, etc... y de singulares transiciones entre los mismos. Aunque esta riqueza ha ido mermando, día tras día, como consecuencia de la degradación de muchas áreas de su territorio. Tal deterioro trae causa en el desarrollo socioeconómico que Galicia ha experimentado durante el pasado siglo; éste, por una parte, ha implicado un radical cambio en la actividad de la sociedad gallega - se ha abandonado el desarrollo de actividades agrícolas, ganaderas, o silvícolas para pasar a realizar actividades industriales y de servicios, esencialmente ligadas al ámbito turístico- $-\mathrm{y}$, por otra parte, ha dado lugar a un fuerte crecimiento urbanístico que, en muchas ocasiones, se ha producido sin control alguno.

No obstante, afortunadamente, parece que esta tendencia negativa ha llegado a un punto de inflexión, ya que se puede observar como, poco a poco, la sociedad gallega y sus representantes políticos van tomando conciencia de la importancia del paisaje, no sólo como recurso económico de gran valor sino también como elemento integrante de la cultura propia y, en consecuencia, la primera exige y los segundos han comenzado a adoptar las medidas necesarias para preservar la riqueza paisajística gallega ${ }^{1}$.

Así, lentamente, la antedicha toma de conciencia se ha ido traduciendo en la introducción del paisaje como elemento a tutelar en diversas normas ${ }^{2}$, relacionadas,

\footnotetext{
${ }^{1}$ Sirva como un importante y reciente ejemplo de esta toma de conciencia el Informe do Valedor do Pobo del año 2006 (BOPG, de 21 de enero de 2008).

2 Para un análisis de las mismas, vid. MARTÍNEZ NIETO, A., "La contaminación del paisaje", Actualidad Administrativa, núm. 20, 1998, pp. 440ss. y DE VICENTE GONZÁLEZ, J. L., "Normas de aplicación directa y protección del paisaje en la Ley de Cantabria 2/2001, de 25 de junio. ¿Límites a la discrecionalidad de la Administración o conceptos jurídicos indeterminados?", Revista de Estudios de la Administración Local, núm. 292-293, 2003, pp. 271-327.
} 
fundamentalmente, con la ordenación del territorio y el urbanismo ${ }^{3}$ y con el medio ambiente y los recursos naturales ${ }^{4}$.

De entre estas normas, es necesario destacar dos, en la medida en la que constituyen dos hitos importantes hacia el establecimiento de una tutela jurídica del paisaje en Galicia singularizada, directa y global $^{5}$.

En primer lugar, se halla la Ley 1/1995, de 2 enero, de Protección del Medio Ambiente de Galicia. Esta norma, por una parte, en su artículo 2, fija, como un criterio inspirador de la misma, el principio de utilización racional y de defensa de los recursos naturales y el paisaje, y, por otra parte, en su artículo 4, señala como un elemento a proteger el paisaje. En este segundo sentido, profundiza el artículo 20.1 de la misma al obligar a la Administración autonómica a redactar inventarios, como fase previa a la catalogación, de los distintos espacios, sectores ambientales y ecosistemas que haya que proteger, entre los cuales menciona expresamente el paisaje. Como se puede observar, esta Ley en diversos preceptos contempla el paisaje como un elemento digno de protección desde la perspectiva ambiental ${ }^{6}$.

En segundo lugar, y dando un paso más hacia una tutela específica para el paisaje, se encuentra la Ley 9/2001, de 21 agosto, de Conservación de la Naturaleza de Galicia.

3 Vid. la Ley 9/2002, de 30 diciembre, de Ordenación Urbanística y Protección del Medio Rural, modificada por la Ley 2/2010, de 25 de marzo. En esta norma se contienen numerosos preceptos de relevancia en esta materia. Entre ellos se pueden destacar el artículo 32.2.g que delimita el suelo rústico de protección del paisaje y el artículo 38 que establece los usos permitidos en el mismo.

4 Vid. la Ley 8/2002, de 18 de diciembre, de Protección del Ambiente Atmosférico de Galicia; Ley 5/2006, de 30 de junio, de Protección, Conservación y Mejora de los Ríos Gallegos, o la Ley 3/2008, de 23 de mayo, de Minería de Galicia.

${ }^{5}$ La consideración del paisaje como un concepto jurídico diferenciado es un fenómeno bastante reciente, no sólo en Galicia sino en España. La existencia de una legislación específica en materia de tutela del paisaje es algo muy reciente, hasta hace poco ésta era una cuestión accesoria regulada, de forma incidental y dispersa, en normas sobre medio ambiente, urbanismo, recursos naturales o patrimonio.

Sobre esta cuestión, vid:: MARTÍN-RETORTILLO BAQUER, L., "Problemas jurídicos de la tutela del paisaje", Revista de Administración Pública, núm. 71, 1973, pp. 423-442; MARTÍNEZ NIETO, A., "La protección del paisaje en el Derecho español (I)", Actualidad Administrativa, núm. 32, 1993, pp. 397-411 y "La protección del paisaje en el Derecho español (II)", Actualidad Administrativa, núm. 33, 1993, pp. 413-430; FERNÁNDEZ RODRÍGUEZ, C., La protección del paisaje. Un estudio de Derecho español y comparado, Marcial Pons, Madrid-Barcelona, 2007, p. 27ss.; y CANALES PINACHO, F. y OCHOA GÓMEZ, P., "La juridificación del paisaje o de cómo convertir un criterio esencialmente estético en un bien jurídico objetivable”, Diario La Ley, núm. 7183, 2009, pp. 1-34.

${ }^{6}$ Vid. un comentario crítico a esta ley en NOGUEIRA LÓPEZ, A., "La regulación medioambiental en la Comunidad Autónoma de Galicia (Ley de Protección Ambiental de Galicia y decretos de desarrollo)", Revista Andaluza de Administración Pública, núm. 24, 1995, pp. 319-337. Sobre las pautas mínimas para la conclusión de acuerdos voluntarios, vid. NOGUEIRA LÓPEZ, A., "La actividad de fomento para la protección de la atmósfera", en prensa. 
Esta norma, en su artículo 8, define como espacios naturales protegidos aquellos espacios, declarados como tales, que contengan elementos o sistemas naturales de particular valor, interés o singularidad, tanto debidos a la acción y evolución de la naturaleza como derivados de la actividad humana. Por su parte, el artículo 9.1.f, enumera como una categoría dentro de esos espacios naturales protegidos la de "Paisaje Protegido”. El artículo 15 de esta Ley disciplina dicha categoría, cuya declaración de conformidad con el artículo 24 de la misma corresponde por Decreto al Consello de la Xunta de Galicia, a propuesta de la Consellería competente en materia de medio ambiente, estableciendo:

"1. Los paisajes protegidos son espacios que, por sus valores singulares, estéticos y culturales o bien por la relación armoniosa entre el hombre y el medio natural, sean merecedores de una protección especial.

2. El régimen de protección de los paisajes protegidos estará dirigido expresamente a la conservación de las relaciones y procesos, tanto naturales como socioeconómicos, que han contribuido a su formación y hacen posible su pervivencia" $"$.

\footnotetext{
${ }^{7}$ Responde este precepto a lo dispuesto en la normativa básica estatal, en concreto, a lo establecido en el artículo 34 de la Ley 42/2007, de 13 de diciembre, del Patrimonio Natural y de la Biodiversidad que preceptúa:
}

"1. [Los] Paisajes Protegidos son partes del territorio que las Administraciones competentes, a través del planeamiento aplicable, por sus valores naturales, estéticos y culturales, y de acuerdo con el Convenio del paisaje del Consejo de Europa, consideren merecedores de una protección especial.

2. Los objetivos principales de la gestión de los Paisajes Protegidos son los siguientes:

a) La conservación de los valores singulares que los caracterizan.

b) La preservación de la interacción armoniosa entre la naturaleza y la cultura en una zona determinada.

3. En los Paisajes Protegidos se procurará el mantenimiento de las prácticas de carácter tradicional que contribuyan a la preservación de sus valores y recursos naturales".

Este precepto, de acuerdo con la Disposición Final Segunda de dicha Ley, tiene carácter de legislación básica sobre protección del medio ambiente, de conformidad con lo dispuesto en el artículo 149.1.23 de la Constitución. Sobre la tutela por los tribunales del paisaje en el ámbito de esta figura se pueden citar: la sentencia del Tribunal Supremo de 10 de diciembre de 2009, Sala de lo Contencioso-Administrativo, recurso núm. 4384/2005; la sentencia del Tribunal Superior de Justicia de Asturias de 26 de julio de 1996, Sala de lo Contencioso-Administrativo, recurso núm. 1620/1994; la sentencia del Tribunal Superior de Justicia de las Islas Baleares de 1 de junio de 2001, Sala de lo Contencioso-Administrativo, recurso núm. 332/1997; la sentencia del Tribunal Superior de Justicia de Murcia de 9 de noviembre de 2001, Sala de lo Contencioso-Administrativo, recurso núm. 1007/2000 y la sentencia del Tribunal Superior de Justicia de la Comunidad Valenciana de 8 de octubre de 2008, Sala de lo Contencioso-Administrativo, recurso núm. 1014/2006. En esta Ley 9/2001 también se pueden encontrar referencias al paisaje en otros preceptos, como el artículo 32 que disciplina el contenido de los planes de ordenación de los recursos naturales o el artículo 63 que regula las infracciones menos graves. 
Es evidente, que esta norma contiene ya una tutela del paisaje más concreta y singularizada que la Ley de 1995, aunque todavía no regula el paisaje como un fenómeno global, sino como un elemento localizado y puntual ${ }^{8}$.

Finalmente, tras estos dos importantes precedentes, se produce la aprobación de la Ley 7/2008, de 7 de julio, de Protección del Paisaje de Galicia (en adelante, LPPG), con la que se incorpora al Ordenamiento gallego una regulación general del paisaje, entendido como todo el territorio de la Comunidad Autónoma y no sólo ciertas partes del mismo que pueden presentar un valor especial o singular ${ }^{9}$. Se trata, sin duda, de una regulación importante, dado que constituye la tercera regulación de este tipo que se aprueba en España: la preceden en Valencia, la Ley 4/2004, de 30 de junio, de Ordenación del Territorio y Protección del Paisaje (en adelante, LVOTPP), y en Cataluña, la Ley 8/2005, de 8 de junio, de Protección, Gestión y Ordenación del Paisaje (en adelante, LCPGOP).

Esta Ley nace con la vocación de complementar, en el sentido de incrementar la protección y promoción jurídica del paisaje, y no de substituir a las normas antes citadas. Así, como prueba de esta afirmación, se puede señalar que tras su aprobación se han dictado los Decretos 263/2008, de 13 de noviembre, por el que se declara paisaje protegido el "Val do río Navea" y 294/2008, de 11 de diciembre, por el que se declara paisaje protegido los "Penedos de Pasarela e Traba", en los que se puede observar como estas normas se aplican de forma conjunta.

Por último, para concluir esta breve introducción, hay que subrayar que el presente trabajo tan solo pretende, con ánimo crítico, dar cuenta de cuál es la regulación de la protección del paisaje contenida en la citada LPPG, esencialmente, confrontándola, a este efecto, con sus predecesoras en otras Comunidades Autónomas.

\footnotetext{
${ }^{8}$ Para análisis de los precedentes normativos en materia de regulacion del paisaje en la Comunidad Autónoma de Galicia, vid. DÍAZ OTERO, A., "El valor jurídico del paisaje en el derecho público gallego", Corts: Anuario de Derecho Parlamentario, núm. 21, 2009, p. 141ss.

${ }^{9}$ Vid. NOGUEIRA LÓPEZ, A., SANZ LARRUGA, F. J., "Galicia: los afanes por aprobar las leyes y planes ambientales pendientes en el final de la legislatura”, López Ramón, F. (coord.), Observatorio de políticas ambientales 2009, Thomson Reuters, Cizur Menor, 2009, pp. 525-564.
} 


\section{LA LEY 7/2008, DE 7 DE JULIO, DE PROTECCIÓN DEL PAISAJE DE}

\section{GALICIA}

\section{Marco competencial}

El Estatuto de Autonomía de Galicia, en su artículo 27.30 establece que es competencia exclusiva de la Comunidad Autónoma el dictar normas adicionales sobre protección del medio ambiente y del paisaje, en los términos del artículo 149.1.23 de la Constitución Española, precepto que, a su vez, señala que el Estado tiene competencia exclusiva para dictar la legislación básica sobre protección del medio ambiente, sin perjuicio de las facultades de las Comunidades Autónomas de establecer normas adicionales de protección.

En consecuencia, en esta materia corresponde al Estado dictar la legislación básica que fije un mínimo común denominador normativo en materia de protección de estos bienes jurídicos y a las Comunidades Autónomas desarrollar dicha normativa $y$, eventualmente, aprobar normas adicionales de protección.

Hay que destacar que en el precepto citado del Estatuto de Galicia se reconoce como título competencial autónomo "el paisaje" -si bien ligado al medio ambiente- el cual no aparece en la Constitución, constituyendo así el Estatuto gallego un texto pionero en el camino de la singularización de la tutela del paisaje ${ }^{10}$.

\footnotetext{
${ }^{10}$ Posteriormente se recogerá este título en: el artículo 28.3 de la Ley Orgánica 4/1983, de 25 de febrero, de Estatuto de Autonomía de Castilla-León, disposición hoy contenida en el artículo 70.1.35 de la Ley Orgánica 14/2007, de 30 noviembre; el artículo 37.3 de la Ley Orgánica 8/1982, de 10 de agosto, de Estatuto de Autonomía de Aragón en la redacción de la Ley Orgánica 5/1996, de 30 diciembre, disposición hoy contenida en el artículo 71.22 de la Ley Orgánica 5/2007, de 20 de abril, de reforma del Estatuto de Autonomía de Aragón; el artículo 9.1 de la Ley Orgánica 3/1982, de 9 de junio, de Estatuto de Autonomía de La Rioja, en la redacción que le dió Ley Orgánica 2/1999, de 7 enero o en el artículo 149.1 de la Ley Orgánica 6/2006, de 19 julio, de Estatuto de Autonomía de Cataluña. En estos y en otros textos estatutarios, el paisaje, en concreto su protección y fomento, aparece, en ocasiones, como un principio rector u objetivo a alcanzar. Entre dichos textos, se pueden enumerar: el artículo 12.3.6 de la Ley Orgánica 6/1981, de 30 diciembre, de Estatuto de Autonomía de Andalucía, hoy reproducido en el artículo 37 de la Ley Orgánica 2/2007, de 19 marzo, de Estatuto de Autonomía de Andalucía; el artículo 4.4.g de la Ley Orgánica 9/1982, de 10 agosto, de Estatuto de Autonomía de Castilla-La Mancha; el artículo 23 de la Ley Orgánica 2/1983, de 25 febrero, de Estatuto de Autonomía de las Illes Balears, hoy reproducido en la Ley Orgánica 1/2007, de 28 febrero, de reforma del Estatuto de Autonomía de las Illes Balears; el artículo 5.2.f de la Ley Orgánica 1/1995, de 13 marzo, de Estatuto de Autonomía de Ceuta y de la Ley Orgánica 2/1995, de 13 marzo, de Estatuto de Autonomía de Melilla, o el artículo 46.4 de la Ley Orgánica 6/2006, de 19 julio, de Estatuto de Autonomía de Cataluña. Finalmente, hay que señalar que algunos de los Estatutos de segunda generación también reconocen el derecho de los ciudadanos a gozar del paisaje, en este sentido se pueden citar, por ejemplo: el artículo 27.1 de la Ley Orgánica 6/2006, de 19 julio, de Estatuto de Autonomía de Cataluña o el artículo 28.1 de la Ley Orgánica 2/2007, de 19 marzo, de Estatuto de Autonomía de Andalucía. El incorporar una parte dogmática a los Estatutos de Autonomía ha generado en la doctrina una viva polémica acerca de su legitimidad constitucional y
} 
Por lo que respecta a la LPPG, el Parlamento gallego a la hora de dictarla además de basarse en el citado título competencial, invoca el artículo 27.3 del Estatuto de Autonomía de Galicia relativo a la competencia exclusiva de la Comunidad Autónoma de Galicia en materia de ordenación del territorio, urbanismo y vivienda.

\section{Objeto, fin y ámbito}

La LPPG tiene por objeto, de acuerdo con su artículo 1, el reconocimiento jurídico, la protección, la gestión y la ordenación del paisaje de Galicia. Éste, de conformidad con el artículo 3.1.a de la LPPG, es cualquier parte del territorio gallego tal y como la percibe la población, cuyo carácter sea el resultado de la acción y de la interacción de factores naturales y humanos ${ }^{11}$.

La LPPG tiene como fin preservar y ordenar todos los elementos que configuran el paisaje de Galicia en el marco del desarrollo sostenible, entendiendo que el paisaje tiene una dimensión global de interés general para la comunidad gallega, por cuanto trasciende a los campos ambientales, culturales, sociales y económicos. Por ello, dado este carácter transversal, la LPPG impulsa la plena integración del paisaje en todas las políticas sectoriales que incidan en el mismo.

Las disposiciones de la LPPG, de conformidad con el artículo 4, se aplicarán a todo el territorio de Galicia, ya sean áreas naturales, rurales, urbanas y periurbanas, así como aquellas otras áreas de elevado valor ambiental y cultural, e incluso los paisajes degradados, comprendiendo asimismo las zonas terrestres, marítimo-terrestres y las aguas interiores ${ }^{12}$.

Finalmente, hay que señalar que la aprobación de la LPPG responde a la necesidad de

utilidad, vid. sobre la misma y sobre la eficacia de estos derechos: DÍEZ-PICAZO, L., “¿Pueden los Estatutos de Autonomía declarar derechos, deberes y principios?", Revista Española de Derecho Constitucional, núm. 78, 2007, p. 63ss.; "De nuevo sobre las declaraciones estatuarias de derechos: respuesta a Francisco Caamaño", Revista Española de Derecho Constitucional, núm. 81, 2007, p. 63ss.; CAAMAÑO DOMÍNGUEZ, F., "Sí, pueden (Declaraciones de derechos y Estatutos de Autonomía)", Revista Española de Derecho Constitucional, núm. 79, 2007, p. 33ss.; EXPÓSITO, E., "La regulación de los Derechos en los nuevos Estatutos de autonomía", Revista de Estudis Autonòmics i Federals, núm. 5, 2007, p. 147ss.; MARTÍNEZ LÓPEZ-MUÑIZ, J. L., "Estatutos de Autonomía y Declaraciones de Derechos", Derechos Fundamentales y otros estudios en homenaje al prof. Dr. Lorenzo MartínRetortillo, vol. I, Gobierno de Aragón et al., Zaragoza, 2008, p. 161ss.; y ORTEGA ÁLVAREZ, L., "Los derechos ciudadanos en los nuevos estatutos de autonomía", Derechos Fundamentales ... cit., p. 185ss.

${ }^{11}$ Se recoge en este precepto literalmente la definición contenida en el artículo 1.a del CEP.

${ }^{12}$ Este ámbito se corresponde esencialmente con el exigido por el artículo 2 del CEP. 
dar cumplimiento a las disposiciones del Convenio Europeo del Paisaje (en adelante, CEP), el cual fue aprobado en Florencia el 20 de octubre de 2000 a propuesta del Consejo de Europa ${ }^{13}$ y fue ratificado por el Reino de España el 6 de noviembre de 2007, entrando en vigor para el mismo el 1 de marzo del $2008^{14}$.

\section{Principios rectores en materia de paisaje}

El artículo 2.1 de la LPPG dispone que los poderes públicos, en sus actuaciones en materia de paisaje, se deben inspirar en los principios enumerados en el apartado segundo del antedicho precepto. En realidad, en el artículo 2.2 de la LPPG, no se contienen principios inspiradores formulados de un modo técnicamente preciso, sino que en el mismo se recogen una serie de manifestaciones de dichos principios, los cuales han de ser inferidos de las mismas.

Así las cosas, se puede afirmar, a luz del contenido de esta disposición, que las actuaciones de los poderes públicos gallegos deben basarse en los siguientes principios: a) reconocimiento jurídico de la relevancia del paisaje; b) protección del paisaje; c) promoción del paisaje y d) colaboración interadministrativa y colaboración públicoprivada en la protección y fomento del paisaje.

A continuación se explicará cada uno de estos principios y sus principales manifestaciones contenidas en la LPPG.

\subsection{Principio de reconocimiento jurídico de la relevancia del paisaje}

De conformidad, con el artículo 2.2.a de la LPPG, los poderes públicos gallegos han de reconocer jurídicamente el paisaje, como elemento importante del entorno y del

\footnotetext{
${ }^{13}$ Entre los antecedentes inmediatos del CEP se puede citar la Carta del Paisaje Mediterráneo, elaborada por las regiones de Andalucía, Languedoc-Roussillon, Toscana y Veneto y adoptada por la Conferencia de Poderes Locales y Regionales del Consejo de Europa.

14 Sobre el contenido, alcance y significado de este documento, vid.: ZOIDO NARANJO, F., "La Convención Europea del Paisaje y su aplicación en España”, Ciudad y Territorio. Estudios Territoriales, núm. 23 (128), 2001, pp. 275-281; PRIEUR, M., "La Convención Europea del Paisaje", Revista Andaluza de Administración Pública, núm. 50, 2003, pp. 19-25; LASAGABASTER HERRARTE, I., LAZCANO BROTÓNS, I., "Protección del paisaje, ordenación del territorio y espacios naturales protegidos", Revista Vasca de Administración Pública, núm. 70, 2004, p. 128ss.; FABEIRO MOSQUERA, A., "La protección del paisaje: su creciente importancia en el ámbito internacional y la dispersión de instrumentos jurídicos para su protección integral en el Derecho español", Revista Española de Derecho Administrativo, núm. 131, 2006, p. 533ss.; FERNÁNDEZ RODRÍGUEZ, C., La protección del paisaje..., cit., p. 82ss.
} 
bienestar humano, indicador de la calidad de vida de las personas y componente fundamental del patrimonio natural y cultural de Galicia, expresión de la identidad $\operatorname{propia}^{15}$.

Para dotar de una mayor fuerza a este principio, quizás, hubiese sido oportuno incorporar a la LPPG un artículo que precisase cuáles son las finalidades que han de perseguir las actuaciones de los poderes públicos en esta materia ${ }^{16}$.

\subsection{Principio de ordenación, gestión y protección del paisaje}

Este principio se traduce, esencialmente, en dos mandatos para los poderes públicos gallegos.

En primer lugar, de acuerdo con el artículo 2.2.b de la LPPG, dichos poderes públicos han de defender y preservar el paisaje, favoreciendo una relación armónica y respetuosa entre la gente y su entorno y promoviendo un uso racional y ordenado del territorio, que tenga en cuenta los valores naturales y culturales de los paisajes. Como garantía de esa relación armónica entre los habitantes y su entorno, el artículo 2.2.c de la LPPG,

\footnotetext{
${ }^{15}$ El reconocimiento jurídico del paisaje, en los términos previstos en el citado artículo 2.2.a de la LPPG, es una de las medidas generales a las que se comprometen los Estados firmantes del CEP, de acuerdo con el artículo 5.a del mismo.

${ }^{16}$ Podría haber servido de modelo el artículo 8 de la LCPGOP que dispone:
}

"Las actuaciones que se ejecuten sobre el paisaje pueden tener, entre otras, las finalidades siguientes:

a) La preservación de los paisajes que, por su carácter natural o cultural, requieren intervenciones específicas e integradas.

b) La mejora paisajística de las periferias y de las vías de acceso a las ciudades y villas, así como la eliminación, reducción y traslado de los elementos, usos y actividades que las degradan.

c) El mantenimiento, mejoramiento y restauración de los paisajes agrícolas y rurales.

d) La articulación armónica de los paisajes, con una atención particular hacia los espacios de contacto entre los ámbitos urbano y rural y entre los ámbitos terrestre y marino.

e) La elaboración de proyectos de integración paisajística de áreas de actividades industriales y comerciales y de las infraestructuras.

f) El fomento de las actuaciones de las administraciones locales y de las entidades privadas en la promoción y protección del paisaje.

g) La adquisición de suelo para incrementar el patrimonio público de suelo en las áreas que se consideren de interés para la gestión paisajística.

h) La atribución de valor al paisaje como recurso turístico".

En esta línea, durante la tramitación de la LPPG, el GPPG introdujo una enmienda de adición de un artículo 7 bis. 
introducido en la tramitación parlamentaria de esta norma ${ }^{17}$, reconoce a las personas que viven en las zonas de especial interés paisajístico el derecho a un desarrollo económico, cultural y social, equilibrado y sostenible.

En segundo lugar, según el artículo 2.2.d de la LPPG, los poderes públicos gallegos han de diseñar y aplicar políticas de paisaje ${ }^{18}$. El artículo 5 de la LPPG, insiste en esta necesidad, al disponer que los poderes públicos velarán para que, en el ámbito de su competencia y dependiendo de la naturaleza de cada territorio, se adopten las medidas específicas necesarias para la protección, gestión y ordenación del paisaje, en la medida en que esto exige el diseño e implica la ejecución de políticas de paisaje.

Las políticas de paisaje, se definen por el artículo 3.b de la LPPG, como la formulación por parte de las autoridades públicas competentes de los principios generales y de las estrategias y directrices que permiten la adopción de medidas específicas orientadas a la protección, gestión y planificación de los paisajes ${ }^{19}$.

Estos tres fines — protección, gestión y planificación de los paisajes - de las políticas de paisaje se explican por el artículo 6 de la LPPG del siguiente modo:

- La ordenación del paisaje comprende la realización de todas aquellas acciones que presentan un carácter prospectivo particularmente acentuado con vistas a mantener, mejorar, restaurar o regenerar paisajes ${ }^{20}$.

- La gestión del paisaje integra todas aquellas acciones que, desde una perspectiva de uso sostenible del territorio, garantizan el mantenimiento regular del paisaje, mediante el control de las transformaciones inducidas por los procesos sociales, económicos y ambientales $^{21}$.

- La protección del paisaje engloba todas aquellas acciones que tienen como fin la preservación y conservación de los elementos más significativos y característicos de un

\footnotetext{
${ }^{17}$ Vid. BOPG, de 16 de abril, de 22 de mayo, de 11 de junio y de 16 de junio de 2008.

${ }^{18} C f r$ artículo 5.b del CEP.

${ }^{19} \mathrm{Cfr}$. artículo 1.b del CEP.

${ }^{20}$ Cfr. artículo 1.f del CEP. Hay que destacar que la redacción de la LPPG es, quizás, un poco más restrictiva que la del CEP, ya que no incluye el término "crear".

${ }^{21} C f r$. artículo 1.e del CEP.
} 
paisaje, justificados por su valor patrimonial como resultado de su configuración natural o de la intervención humana sobre el medio ${ }^{22}$.

Finalmente, hay que señalar que, según el artículo 2.2.d de la LPPG, las políticas de paisaje han de integrarse en las políticas de protección ambiental, de ordenación territorial y urbanística, en materia cultural, turística, agraria, social o económica, y en aquellas otras que puedan tener un impacto directo o indirecto sobre los paisajes ${ }^{23}$. Este mandato se reitera también en el artículo 5.2 de la LPPG que establece que los poderes públicos integrarán la consideración del paisaje en las políticas de ordenación territorial y urbanístico, y en sus políticas ambientales, del patrimonio cultural, agrícolas, forestales, sociales, turísticas, industriales y económicas, así como en cualquier otra política sectorial que pueda producir un impacto directo o indirecto sobre el paisaje ${ }^{24}$.

\footnotetext{
${ }^{22}$ Cfr. artículo 1.d del CEP.

${ }^{23}$ Cfr. artículo 5.d del CEP.

24 Como ejemplo de esta integración se puede citar el artículo 42 "Condiciones generales de las edificaciones en el suelo rústico" de la Ley 9/2002, de 30 diciembre, de Ordenación Urbanística y Protección del Medio Rural, modificada por la Ley 2/2010, de 25 de marzo, que establece:
}

"1. Para otorgar licencia o autorizar cualquier clase de edificaciones o instalaciones en el suelo rústico deberá justificarse el cumplimiento de las siguientes condiciones: [...]

b) Prever las medidas correctoras necesarias para minimizar la incidencia de la actividad solicitada sobre el territorio, así como todas aquellas medidas, condiciones o limitaciones tendentes a conseguir la menor ocupación territorial y la mejor protección del paisaje, los recursos productivos y el medio natural, así como la preservación del patrimonio cultural y la singularidad y tipología arquitectónica de la zona.

c) Cumplir las siguientes condiciones de edificación: [...]

-El volumen máximo de la edificación será similar al de las edificaciones tradicionales existentes en el suelo rústico del entorno [...] En todo caso, habrán de adoptarse las medidas correctoras necesarias para garantizar el mínimo impacto visual sobre el paisaje y la mínima alteración del relieve natural de los terrenos.

-Las características tipológicas de la edificación habrán de ser congruentes con las tipologías rurales tradicionales del entorno, en particular, las condiciones de volumetría, tratamiento de fachadas, morfología y tamaño de los huecos, y soluciones de cubierta, que, en todo caso, estarán formadas por planos continuos sin quiebras en sus vertientes. Salvo en casos debidamente justificados por la calidad arquitectónica del proyecto, los materiales a utilizar en la terminación de la cubrición serán teja cerámica y/o pizarra, según la tipología propia de la zona $[\ldots]$

-Las características estéticas y constructivas y los materiales, colores y acabados serán acordes con el paisaje rural y las construcciones tradicionales del entorno. En tal sentido, para el acabado de las edificaciones se empleará la piedra u otros materiales tradicionales y propios de la zona. En casos justificados por la calidad arquitectónica de la edificación, podrán emplearse otros materiales acordes con los valores naturales, el paisaje rural y las edificaciones tradicionales del entorno.

-Los cierres y vallados serán preferentemente vegetales, sin que los realizados con material opaco de fábrica sobrepasen la altura de 1 metro, salvo en parcelas edificadas, donde podrán alcanzar 1,50 metros. En todo caso, deben realizarse con materiales tradicionales 


\subsection{Principio de promoción del paisaje}

El dar adecuado cumplimiento a este principio implica:

- Sensibilizar a la sociedad gallega sobre el valor, importancia y funciones del paisaje, así como acerca de los procesos de transformación que experimenta (art. 2.2.g de la LPPG $)^{25}$. El artículo 14.1 de la LPPG, que más adelante se analizará, impone determinadas obligaciones en este campo a la Xunta de Galicia.

- Promover el estudio y la formación en materia de paisaje, desarrollando actividades específicas sobre la importancia, protección, gestión y ordenación del paisaje (art. 2.2.h de la LPPG) ${ }^{26}$. El artículo 14.2 de la LPPG, que será objeto de estudio más adelante, prevé diversas acciones en este ámbito.

3.4. Principio de colaboración interadministrativa y colaboración público-privada en la protección y fomento del paisaje

Este principio se traduce, inicialmente, en:

- Fomentar la coordinación y la colaboración entre las distintas Administraciones públicas en materia de paisaje (art. 2.2.e de la LPPG). En este sentido, por una parte, en el artículo 7 de la LPPG, se ordena a la Xunta de Galicia que impulse la cooperación con todas las Administraciones públicas con competencia en el territorio, especialmente con las Administraciones locales, con el objetivo de promover el desarrollo de políticas comunes, debidamente coordinadas y programadas, que aseguren el cumplimento de los fines de ordenación, gestión, promoción del paisaje perseguidos por la LPPG, y, por otra parte, el artículo 5.3 dispone que la Xunta de Galicia ha de promover acciones de cooperación transfronteriza en los distintos niveles territoriales, para la elaboración de políticas y programas comunes en materia de paisaje, así como con las Comunidades Autónomas que limiten con Galicia, en esta línea, en particular, el artículo 12.4 de la LPPG ordena a la Administración ambiental gallega que, en aquellas áreas geográficas

del medio rural en que se emplacen, no permitiéndose el empleo de bloques de hormigón u otros materiales de fábrica, salvo que sean debidamente revestidos y pintados en la forma que reglamentariamente se determine $[\ldots] "$.

${ }^{25}$ Cfr. artículo 6.A del CEP.

${ }^{26} C f r$. artículo 6.B del CEP. Hay que señalar que las previsiones de la LPPG en esta materia son más cicateras que las del CEP. 
transfronterizas o interautonómicas que cuenten con algún espacio natural protegido, impulse la elaboración de planes de acción conjuntos en materia de paisaje ${ }^{27}$.

- Establecer mecanismos de participación social en la toma de decisiones y en la definición de las políticas de paisaje, sobre todo con las Entidades locales (art. 2.2.f de la LPPG) ${ }^{28}$. En desarrollo de este principio, la LPPG establece diversos procedimientos participativos en sus artículos 9.5 y 10.6 .

\section{Instrumentos jurídicos en materia de paisaje}

La LPPG pone a disposición de los poderes públicos dos tipos de instrumentos para la realización de su objeto ${ }^{29}$ : los instrumentos para la protección, gestión y ordenación del paisaje y los instrumentos de organización, sensibilización y concertación de las políticas de paisaje $\mathrm{e}^{30}$.

\subsection{Instrumentos para la protección, gestión, ordenación y promoción del paisaje}

Estos instrumentos se pueden clasificar en dos grupos, en función de los sujetos que intervienen en los mismos y de las condiciones en las que lo hacen. En primer lugar, se hallan los instrumentos imperativos unilaterales, éstos son obligatorios y su aprobación corresponde a la Administración autonómica, aunque en alguna ocasión su elaboración corresponda a un particular ${ }^{31}$. En segundo lugar, se encuentran los instrumentos voluntarios bilaterales o multilaterales, en los que diferentes sujetos libremente, en condiciones de igualdad, acuerdan la adopción de una serie de medidas para la promoción y tutela del paisaje.

\footnotetext{
${ }^{27}$ Cfr. artículo 9 del CEP.

${ }^{28}$ Cfr. artículo 5.c del CEP.

${ }^{29}$ Hay que señalar, no obstante, que éstos no son los únicos instrumentos existentes para lograr los citados fines. Así, se pueden destacar los Planes Especiales de Protección de Paisajes de Interés regulados por el artículo 69 de la Ley 9/2002, de 30 diciembre, de Ordenación Urbanística y Protección del Medio Rural, modificada por la Ley 2/2010, de 25 de marzo.

${ }^{30}$ Cfr. artículo 6.C, D y E del CEP.

${ }^{31}$ De conformidad con el artículo 16 del Decreto 316/2009, de 4 junio, por el que se establece la estructura orgánica de la Consellería de Medio Ambiente, Territorio e Infraestructuras, el elenco de instrumentos que a continuación se estudiarán no constituyen un númerus clausus.
} 
A. Instrumentos imperativos unilaterales

De conformidad con el artículo 8 de la LPPG, son instrumentos para la protección, gestión y ordenación del paisaje de Galicia: los Catálogos del Paisaje, las Directrices de Paisaje, los Estudios de Impacto e Integración Paisajística y los Planes de Acción del Paisaje en Áreas Protegidas ${ }^{32}$.

\section{A.1. Catálogos del Paisaje}

Estos instrumentos se disciplinan en el artículo 9 de la LPPG, donde se comprende su definición, su contenido esencial y el procedimiento a seguir en su elaboración.

Así, el párrafo primero de dicho artículo define los Catálogos del Paisaje como los documentos de referencia que, fundamentándose en las distintas áreas geográficas, morfológicas, urbanas y litorales existentes en el territorio gallego delimitan, en base a los diferentes estudios y trabajos existentes en la materia, las grandes áreas paisajísticas de Galicia, identificando los diversos tipos de paisajes existentes en cada una de ellas y sus características diferenciales ${ }^{33}$.

\footnotetext{
${ }^{32}$ En el ámbito de la Comunidad Valenciana, de acuerdo con el artículo 30 de la LVOTPP, son instrumentos de ordenación y gestión del paisaje: los Planes de Acción Territorial y, en su ausencia o como complemento de los mismos, los Planes Generales. Ambos tipos de planes, de acuerdo con el apartado segundo de este precepto, deberán contener un Estudio de Paisaje. Por su parte, el Decreto 120/2006, de 11 de agosto, por el que se aprueba el Reglamento de Paisaje de la Comunidad Valenciana (en adelante, RPCV), especifica, en su artículo 23, con mayor detalle los instrumentos para la protección, ordenación y gestión del paisaje. De acuerdo con este precepto, éstos son: el Plan de Acción Territorial de Paisaje de la Comunidad Valenciana, los Estudios de Paisaje, los Estudios de Integración Paisajística, los Catálogos de Paisaje y los Programas de Paisaje.
}

Sobre los instrumentos de ordenación y gestión del paisaje en la LVOTPP, vid. MARTÍNEZ MARTÍNEZ, E., "La Ley 4/2004, de ordenación del territorio y protección del paisaje de la Comunidad Valenciana: hacia una ordenación estructural sostenible", Revista Aranzadi de Derecho Ambiental, núm. 9, 2006, p. 315ss.; y La protección del medio natural en la Ley 4/2004, de ordenación del territorio y protección del paisaje de la Comunidad Valenciana, Corts Valencianes, Valencia, 2007, p. 69ss. En Cataluña, los instrumentos de protección, gestión y ordenación del paisaje, se prevén en los artículos 9 a 12 y 14 de la LCPGOP donde se regulan los Catálogos de Paisaje, las Directrices de Paisaje y las Cartas del Paisaje y en el artículo 19 del Decreto 343/2006, de 19 de septiembre, por el que se desarrolla la citada Ley (en adelante, RPC), donde, además de los instrumentos citados, se disciplinan los Estudios e Informes de Impacto e Integración Paisajística.

${ }^{33}$ Como se ha señalado, estos Catálogos también se encuentran regulados en la legislación autonómica valenciana y catalana. No obstante, hay que destacar que mientras que en Galicia y Cataluña son instrumentos de ámbito general que abarcan todo el territorio, en Valencia sólo contemplan las Unidades de Paisaje o Recursos Paisajísticos objeto de protección especial. Por otro lado, también hay que señalar que, en Galicia y Cataluña, ambos instrumentos tampoco se configuran de modo idéntico sino que cumplen diferentes funciones; en Cataluña, los Catálogos definen los objetivos de calidad paisajística para cada unidad de paisaje y recogen las medidas y acciones necesarias para alcanzar dichos objetivos de calidad paisajística, mientras que en Galicia esas funciones le corresponden a las Directrices del Paisaje. 
En cuanto a su contenido, hay que señalar que, según el párrafo segundo del citado artículo 9, los Catálogos del Paisaje han de incluir: en primer lugar, la identificación de los diferentes tipos de paisaje que existen en cada área paisajística; en segundo lugar, un inventario de los valores paisajísticos presentes en cada área paisajística, individuando aquellos ámbitos que, en cada una de ellas, se encuentren en un especial estado de deterioro y que precisen particulares medidas de intervención y protección; en tercer lugar, un análisis de las causas que determinaron la existencia de esos tipos de paisaje, de aquellas que inciden en la actualidad sobre los elementos del paisaje y su evolución futura prevista; en cuarto lugar, un diagnóstico del estado actual del paisaje en cada área paisajística; y, en quinto lugar, la delimitación de las unidades de paisaje presentes en cada área, entendidas como ámbitos territoriales con valores paisajísticos homogéneos y coherentes. Asimismo, en el párrafo tercero del artículo 9, se establece la posibilidad de que en los Catálogos del Paisaje se identifiquen determinadas zonas geográficas como “Áreas de especial interés paisajístico", en atención a los valores naturales y culturales presentes en ellas.

Por lo que respecta a la elaboración de estos Catálogos, hay que analizar dos cuestiones: los órganos competentes para su redacción y aprobación y el procedimiento que ha de seguirse para ello.

La formación de los Catálogos del Paisaje corresponde, según el artículo 9.4 de la LPPG, al Observatorio Gallego del Paisaje ${ }^{34}$ y su aprobación es competencia, de acuerdo con el artículo 9.6 de la LPPG, del Consello de la Xunta de Galicia.

En la elaboración de los proyectos de Catálogos del Paisaje, el Observatorio Gallego del Paisaje ha de tener en cuenta otros Catálogos ya existentes en materia paisajística. Una vez redactados dichos proyectos, según el artículo 9.5 de la LPPG, ha de abrirse un periodo de información pública no inferior a dos meses para que todos los posibles interesados puedan formular las alegaciones que estimen pertinentes. Tras la respuesta a las alegaciones formuladas, los proyectos deben remitirse a la Consellería competente en materia de medio ambiente, para que ésta los someta a estudio de las Consellerías competentes en materia de ordenación del territorio y patrimonio cultural $\mathrm{y}$, posteriormente, los eleve para su aprobación al Consello de la Xunta.

\footnotetext{
${ }^{34}$ La Disposición Adicional Segunda de la LPPG establece que, mientras no se constituya el Observatorio Gallego del Paisaje, la competencia para la elaboración de los Catálogos del Paisaje corresponderá a la Consellería competente en materia de medio ambiente.
} 


\section{A.2. Directrices de Paisaje}

Las Directrices de Paisaje, de conformidad con lo establecido en el artículo 10.1 de la LPPG, son aquellas determinaciones que, basadas en los Catálogos del Paisaje, definen y precisan, para cada unidad de paisaje, los objetivos de calidad paisajística que se pretenden alcanzar ${ }^{35}$. Éstos, según el artículo 3.c de la LPPG, constituyen el planteamiento por parte de las autoridades públicas competentes, para un paisaje concreto, de las aspiraciones de la colectividad en relación a las características paisajísticas de su entorno ${ }^{36}$.

Respecto del contenido mínimo de estas Directrices de Paisaje, el párrafo tercero del citado artículo establece que éstas han de incluir: en primer lugar, la definición de los objetivos de calidad paisajística para cada unidad de paisaje; en segundo lugar, una propuesta de medidas y acciones específicas para alcanzar los objetivos de calidad y de recuperación de aquellas áreas en las que existen ámbitos degradados; en tercer lugar, una descripción de los indicadores de calidad paisajística para el control y seguimiento

\footnotetext{
${ }^{35}$ En la Comunidad Valenciana no se regulan las Directrices de Paisaje de forma independiente, sino que la LVOTPP prevé dos instrumentos complementarios que cumplen una función similar: los Planes de Acción Territorial y los Estudios de Paisaje. Así, el artículo 11.2 de esta Ley dispone que la Generalitat aprobará un Plan de Acción Territorial del Paisaje en el que, además de identificar y proteger los paisajes de relevancia regional en el territorio valenciano, se fijarán directrices y criterios de elaboración de Estudios de Paisaje, de su valoración y de su consecuente protección; mientras que el artículo 31 del mismo texto legal precisa que en los mismos, entre otros aspectos, se establecerán los objetivos de calidad paisajística del ámbito de estudio y el artículo 32 estipula que en ellos se propondrán medidas para la mejora paisajística de los ámbitos degradados y medidas de restauración o rehabilitación paisajística en ámbitos con un elevado grado de deterioro o con una alta incidencia en la percepción del territorio. Para un análisis detenido de la regulación de los Planes de Acción Territorial y de los Estudios de Paisaje en la normativa valenciana sobre paisaje, vid. FERNÁNDEZ RODRÍGUEZ, C., La protección del paisaje... cit., p. 128ss.; y "El estreno de nuestro Derecho en la ordenación paisajística: a propósito de la ordenación y protección del paisaje en la legislación valenciana", Revista de Administración Pública, núm. 172, 2007, p. 382ss. Por su parte, en Cataluña la configuración de las Directrices del Paisaje es muy diferente, como se puede deducir del tenor literal del artículo 12 de la LCPGOP que dispone:
}

"1. Las directrices del paisaje son las determinaciones que, basándose en los catálogos del paisaje, precisan e incorporan normativamente las propuestas de objetivos de calidad paisajística en los planes territoriales parciales o en los planes directores territoriales.

2. Los planes territoriales parciales y los planes directores territoriales determinan los supuestos en que las directrices son de aplicación directa, los supuestos en que son de incorporación obligatoria cuando se produzca la modificación o revisión del planeamiento urbanístico y los supuestos en que las actuaciones requieren un informe preceptivo del órgano competente en materia de paisaje. Los planes territoriales parciales y los planes directores territoriales también pueden determinar cuándo las directrices del paisaje son recomendaciones para el planeamiento urbanístico, para las cartas del paisaje y para otros planes o programas derivados de las políticas sectoriales que afecten al paisaje. En este último supuesto, los planes o programas que se aprueben deben ser congruentes con las recomendaciones de las directrices del paisaje".

${ }^{36} C f r$. artículo 1.c del CEP. 
del estado y evolución de las unidades de paisaje; y en cuarto lugar, una serie de normas y recomendaciones para la definición de los planes urbanísticos y sectoriales y de las estrategias regionales o locales encaminadas a un desarrollo sostenible del territorio, a fin de integrar en ellos los objetivos de calidad paisajística.

Por lo que atañe a la formulación de las Directrices de Paisaje, hay que precisar: a quién le corresponde elaborarlas, cómo se han de realizar y quién debe aprobarlas.

De acuerdo con el artículo 10.6 de la LPPG, la elaboración de los proyectos de Directrices de Paisaje le corresponde a la Consellería competente en materia de medio ambiente y desarrollo sostenible. A la hora de redactar dichos proyectos, de conformidad con el artículo 10.4 de la LPPG, hay que tener en cuenta que estas Directrices han de ser congruentes con las determinaciones que, en materia de paisaje, puedan derivarse de otros instrumentos normativos.

Según este mismo precepto, los trámites que han de seguirse antes de la aprobación de los mismos son: a) la información pública, como mínimo por el plazo de dos meses, este trámite constituye la concreción del artículo 10.2 de la LPPG que establece que, en la medida en que los objetivos de calidad paisajística deben expresar las aspiraciones de la ciudadanía en cuanto a la valoración y grado de compromiso de la colectividad en la protección del paisaje, la determinación de estos objetivos debe realizarse mediante un proceso de participación pública; b) el informe preceptivo de los Ayuntamientos afectados y c) el informe preceptivo de las Consellerías competentes en materia de ordenación del territorio y patrimonio cultural.

Finalmente, hay que señalar que, según el artículo 10.7 de la LPPG, la competencia para la aprobación de los proyectos de Directrices de Paisaje le corresponde al Consello de la Xunta de Galicia.

Las normas recogidas en estas Directrices, de conformidad con el artículo 10.4 de la LPPG, una vez aprobadas, tienen carácter vinculante para los instrumentos de planificación sectorial y urbanística ${ }^{37}$. Además, en esta línea, el artículo 10.5 de la LPPG dispone que la evaluación ambiental de aquellos planes y programas que deban someterse a ella de acuerdo con lo dispuesto en la Ley 9/2006, de 28 de abril, sobre

\footnotetext{
37 En este sentido, el artículo 84 de la Ley 9/2002, de 30 diciembre, de Ordenación Urbanística y Protección del Medio Rural, modificada por la Ley 2/2010, de 25 de marzo, prevé que los proyectos de Planes Generales se sometan a informe sobre su congruencia con los instrumentos previstos en la LPPG.
} 
evaluación de los efectos de determinados Planes y Programas en el Medio Ambiente, han de integrar criterios que tengan como objetivo la protección del paisaje y facilitar su ordenación y gestión. Para ello, el documento de referencia previsto en el artículo 19 de la citada Ley establecerá las pautas y criterios a seguir en la evaluación ambiental del plan y programa e integrará, preceptivamente, las normas que se establezcan en las Directrices de Paisaje.

Quizás, el legislador gallego, para reforzar la fuerza vinculante y eficacia de este instrumento, podría haber incluido algunos preceptos de aplicación directa, en los que se disciplinasen medidas concretas destinadas a propiciar una adecuada integración paisajística en la planificación territorial y urbanística, tal y como se ha hecho en otras Comunidades Autónomas ${ }^{38}$.

\section{A.3. Estudios de Impacto e Integración Paisajística}

De acuerdo con el tenor literal del artículo 11 de la LPPG, los Estudios de Impacto e Integración Paisajística son documentos en los que, por una parte, se evalúan los efectos y repercusiones que un proyecto puede provocar en el paisaje, examinando las repercusiones que pueden tener sobre el paisaje la ejecución de las actuaciones, obras o actividades que se pretenden desarrollar, y en los que, por otra parte, se contienen los

\footnotetext{
38 Así, el artículo 33 de la LVOTPP establece que los instrumentos de ordenación territorial deben incorporar los siguientes criterios:

“a) Adecuación a la pendiente natural del terreno, de modo que ésta se altere en el menor grado posible y se propicie la adecuación a la topografía del terreno, tanto del perfil edificado como del parcelario, de la red de caminos y de las infraestructuras lineales.

b) Impedir la construcción sobre elementos dominantes o en la cresta de las montañas, bordes de acantilados y cúspide del terreno, salvo las obras de infraestructuras y equipamientos de utilidad pública que deban ocupar dichas localizaciones.

c) Incorporación de los elementos topográficos significativos como condicionante de proyecto, tales como laderas y resaltes del relieve, cauces naturales, muros, bancales, caminos tradicionales y otros análogos proponiendo las acciones de integración necesarias para no deteriorar la calidad paisajística".
}

Vid. también los artículos 34, 35 y 36 del mismo texto legal, donde se regulan, respectivamente, las normas de aplicación directa en medio rural, las normas en relación con el paisaje urbano y los programas de imagen urbana. Sobre el carácter vinculante de las Directrices, vid. DÍAZ OTERO, A., "El valor jurídico del paisaje..." cit., p. 161ss. 
criterios y las medidas de integración paisajística que sean necesarias para paliar el impacto de dicho proyecto y lograr su completa y correcta integración paisajística ${ }^{39}$.

Acerca de estos Estudios de Impacto e Integración Paisajística hay que clarificar tres aspectos: a) qué proyectos deben ser objeto de los mismos; b) cuál es su contenido mínimo y c) quienes intervienen en la elaboración y aprobación de estos instrumentos.

Por lo que se refiere a los proyectos que deben ser objeto de Estudio de Impacto e Integración Paisajística hay que señalar que éstos se pueden clasificar en dos conjuntos. El primero, de acuerdo con el artículo 11.1 de la LPPG, se halla compuesto por todos aquellos proyectos que deban someterse al procedimiento de Evaluación de Impacto Ambiental, de acuerdo con lo establecido por la legislación sectorial vigente. El segundo grupo, según el artículo 11.4 de la LPPG, lo integran aquellos proyectos que, si bien no se hallan sujetos a los procedimientos de Evaluación de Impacto Ambiental, pretendan sin embargo realizarse en las zonas geográficas identificadas como "Áreas de especial interés paisajístico" y se encuentren en alguno de los supuestos que el Consello de la Xunta determine reglamentariamente. El Consello de la Xunta, para la determinación de estos supuestos ha de tener en cuenta parámetros como la existencia de espacios naturales protegidos, la distancia respecto de la línea de costa, el volumen de edificación, la superficie afectada por el proyecto, la incidencia sobre los recursos naturales y la presencia de elementos valiosos del patrimonio natural y cultural ${ }^{40}$.

\footnotetext{
${ }^{39}$ En la normativa en materia de paisaje de otras Comunidades Autónomas también se han introducido instrumentos similares. Así, por ejemplo, en la Comunidad Valenciana se prevén los Estudios de Integración Paisajística, regulados en los artículos 48 y ss. del RPCV, los cuales tienen por objeto, de acuerdo con lo dispuesto en el artículo 49, "predecir y valorar la magnitud y la importancia de los efectos que las nuevas actuaciones o la remodelación de actuaciones preexistentes pueden llegar a producir en el carácter del paisaje y en su percepción y determinar estrategias para evitar los impactos o mitigar los posibles efectos negativos" y, en Cataluña se regulan los Estudios de Impacto e Integración Paisajística en los artículos 19ss. del RPC, definidos por el artículo 19 como un "documento técnico destinado a considerar las consecuencias que tiene sobre el paisaje la ejecución de actuaciones, proyectos de obras o actividades y a exponer los criterios adoptados para su integración".

${ }^{40}$ A efectos de la determinación de éstos se puede tener en cuenta la regulación efectuada tanto en Valencia como en Cataluña. En la Comunidad Valenciana, de acuerdo con el artículo 48.4 del RPCV deberán ir acompañados de Estudio de Integración Paisajística:
}

“a) El planeamiento urbanístico de desarrollo contemplado en los apartados b, c, d y f del artículo 38 de la Ley 16/2005, de 30 de diciembre.

b) Las solicitudes de licencias urbanísticas dentro de los conjuntos y sus entornos declarados Bienes de Interés Cultural y dentro de los Espacios Naturales Protegidos.

c) Las solicitudes de Declaraciones de Interés Comunitario.

d) Autorizaciones y licencias en suelo no urbanizable no incluidas en los ámbitos anteriores. 
Estos Estudios, según el artículo 11.2 de la LPPG, han de tener el siguiente contenido: un diagnóstico del estado actual del paisaje (principales componentes, valores paisajísticos, visibilidad y fragilidad del paisaje); las características principales del proyecto; el impacto previsto del proyecto sobre los elementos que configuran el paisaje; la justificación de cómo se incorporan al proyecto los objetivos de calidad paisajística y las determinaciones de las Directrices de Paisaje establecidas para la unidad de paisaje en la que se pretende ejecutar la actuación ${ }^{41}$; y los criterios y medidas a adoptar para alcanzar la integración paisajística del proyecto.

Respecto de la última cuestión - quiénes intervienen en la elaboración y aprobación de los Estudios - hay que señalar, en primer lugar, que le corresponde a las entidades promotoras de dichos proyectos elaborar los Estudios de Impacto e Integración Paisajística y, cuando así proceda, incorporarlos en el Estudio de Impacto Ambiental y, en segundo lugar, que es competencia de la Consellería responsable en materia de medio ambiente emitir el Informe de Impacto e Integración Paisajística dentro de los procedimientos de Declaración y Evaluación del Impacto Ambiental, Informe que resultará integrado en la correspondiente Declaración de Impacto Ambiental ${ }^{42}$.

e) Los proyectos sometidos a evaluación de impacto ambiental al amparo de lo dispuesto en la Ley 2/1989, de 3 de marzo y de su Reglamento de desarrollo aprobado por Decreto $162 / 1990$, de 15 de octubre, sustituyéndose el análisis de impacto visual por el citado estudio conforme a lo señalado en el artículo 58 de este Reglamento.

f) Proyectos de infraestructuras u obras públicas".

A su vez, en Cataluña, el artículo 20 del RPC señala que los Estudios de Impacto e Integración paisajística son preceptivos en los siguientes supuestos:

“a) En aquellas actuaciones, usos, actividades y nuevas construcciones en suelo no urbanizable que se tienen que autorizar por el procedimiento previsto en el artículo 48 del Decreto Legislativo $1 / 2005$, de 26 de julio, por el que se aprueba el Texto Refundido de la Ley de Urbanismo.

b) En los supuestos en que así se requiera por el planeamiento territorial o urbanístico.

c) En todos aquellos otros supuestos en que así lo establezca cualquier ley o disposición de carácter general".

${ }^{41}$ Esta estipulación, precisa el artículo 11.2.d de la LPPG, será preceptiva cuando sean aprobadas las Directrices de Paisaje. Se trata, esta última, de una previsión impropia de un artículo, correspondería que la misma hubiese sido incorporada, por ejemplo, a la Disposición Final Segunda de la LPPG.

42 Para una mayor claridad normativa, sería conveniente que el desarrollo reglamentario de la LPPG incluyese una definición clara de "Informe de Impacto e Integración Paisajística" de la que dicha Ley carece. En este sentido, se podría tomar como modelo el artículo 22.1 del RPC que establece: 2El Informe de impacto e integración paisajística tiene por objeto evaluar la idoneidad y suficiencia de los criterios o las medidas adoptadas en los estudios a que hacen referencia el artículo 19 y siguientes de este Decreto, para integrar en el paisaje las actuaciones, usos, obras o actividades a realizar". 


\section{A.4. Planes de Acción del Paisaje en Áreas Protegidas}

Los Planes de Acción del Paisaje en Áreas Protegidas son documentos que tienen como finalidad la protección, gestión y ordenación del paisaje en aquellos territorios declarados como espacios protegidos, según lo dispuesto en la normativa gallega vigente en materia de conservación de la naturaleza ${ }^{43}$.

Su contenido, de acuerdo con lo dispuesto por el artículo 12.2 de la LPPG, consistirá en una propuesta de medidas para el mantenimiento, mejora, recuperación o regeneración de los paisajes presentes en el área protegida que se ajustará a las determinaciones contenidas en las Directrices de Paisaje para el territorio donde se ubique el espacio protegido, de conformidad con los criterios de calidad paisajística establecidos.

Estos Planes de Acción, según el citado artículo 12.2 de la LPPG, se integrarán en los instrumentos de planificación y ordenación del área protegida, previstos en la normativa gallega vigente en materia de conservación de la naturaleza ${ }^{44}$.

La competencia para impulsar la elaboración de estos Planes de Acción corresponde a la Consellería competente en materia de medio ambiente, a la que el artículo 12.3 de la LPPG encomienda promover que todas las zonas geográficas identificadas en los Catálogos del Paisaje como “Áreas de especial interés paisajístico" dispongan de la protección precisa que permita la preservación de sus valores.

B. Instrumentos voluntarios bilaterales o multilaterales

B.1. Pactos por el paisaje

Según el artículo 14.3 de la LPPG, la Xunta de Galicia debe impulsar la celebración de Pactos por el paisaje como instrumentos de concertación entre las Administraciones públicas, las Entidades locales y los demás agentes económicos y sociales de un determinado territorio que de manera voluntaria deseen llevar a cabo acciones de protección y mejora de los paisajes y de la calidad de vida de los ciudadanos en el marco de una política de desarrollo sostenible.

\footnotetext{
43 Vid. la Ley 9/2001, de 21 agosto, de Conservación de la Naturaleza de Galicia, en particular, los artículos 9, 10, 15 y 24.

${ }^{44}$ Vid. la Ley 9/2001, de 21 agosto, de Conservación de la Naturaleza de Galicia.
} 
Estos Pactos, de conformidad con el mismo precepto, incorporarán en su contenido las actuaciones concretas y específicas que tienen que emprender los diferentes agentes intervinientes para alcanzar los objetivos de calidad paisajística fijados para el ámbito espacial al que se refieran.

De acuerdo con el artículo 14.4 de la LPPG, los Pactos por el paisaje que se establezcan entre la Xunta de Galicia y las Administraciones locales, así como con otros agentes económicos y sociales, habrán de tener en cuenta las recomendaciones y determinaciones de los Catálogos del Paisaje y de las Directrices de Paisaje para ese ámbito geográfico, así como la existencia de espacios o elementos inventariados del patrimonio natural, artístico o cultural ${ }^{45}$.

\section{B.2. Acuerdos voluntarios en Áreas de Especial Interés Paisajístico}

De conformidad con el artículo 14.5 de la LPPG, la Xunta de Galicia, en las Áreas de Especial Interés Paisajístico, ha de favorecer la suscripción de Acuerdos voluntarios entre las personas propietarias de las tierras y las Entidades públicas, con el fin de apoyar y colaborar en la defensa y la conservación de los valores naturales y culturales presentes en estas áreas ${ }^{46}$.

${ }^{45}$ Un instrumento de contenido análogo se prevé en el artículo 14 de la LCPGOP: las Cartas de Paisaje. Éstas se definen, en el párrafo primero del citado artículo, como “instrumentos de concertación de estrategias entre los agentes públicos y los privados para cumplir actuaciones de protección, gestión y ordenación del paisaje que tengan por objetivo mantener sus valores”. Según el artículo 18.5 del RPC, las Cartas de Paisaje han de tener el siguiente contenido:

“a) El diagnóstico de las dinámicas de paisaje.

b) La definición de los objetivos de calidad paisajística a conseguir dentro del ámbito territorial que alcanza la carta de paisaje. Estos objetivos tienen que ser coherentes con los objetivos de calidad establecidos para cada una de las unidades de paisaje definidas en los correspondientes Catálogos de paisaje.

c) Elaboración de un programa de gestión en el que se concreten las acciones específicas que tienen que emprender los diversos agentes, y en el cual tiene que quedar garantizada la participación ciudadana".

El GPPG en la tramitación parlamentaria de la LPPG, a través de sus enmiendas n. 6 al apartado 5 del artículo 8 y n. 13 para añadir un artículo 11 bis, propuso incluir una regulación muy similar a ésta contenida en la normativa catalana.

${ }^{46}$ El futuro desarrollo reglamentario de la LPPG deberá concretar el contenido de estos Acuerdos. En este sentido se podría establecer que en los mismos se recogerán las actuaciones necesarias para garantizar la preservación, mejora y puesta en valor de los paisajes que por su valor natural, visual o cultural requieren de la colaboración público-privada; en particular, en los mismos se preverán: el mantenimiento, mejora y restauración de los paisajes forestales, agropecuarios y rurales; la mejora paisajística de los asentamientos rurales, especialmente mediante la eliminación, reducción y traslado de los elementos, usos y actividades 


\subsection{Instrumentos de análisis, estudio y sensibilización en materia de paisaje}

La LPPG prevé dos instrumentos de organización, sensibilización y concertación de las políticas de paisaje, uno de naturaleza orgánica, el Observatorio Gallego del Paisaje ${ }^{47}$, $\mathrm{y}$, otro de tipo funcional, las acciones de formación, sensibilización, educación y concertación.

\section{A. Observatorio Gallego del Paisaje}

El Observatorio Gallego del Paisaje constituirá, según el artículo 13.1 de la LPPG, una entidad de apoyo y asesoramiento a la Xunta de Galicia $^{48}$ en materia de paisaje, y de colaboración y coordinación con otras Administraciones y sectores de la sociedad ${ }^{49}$.

En cuanto a la naturaleza jurídica del Observatorio, hay que resaltar que el citado artículo 13 en su apartado segundo ${ }^{50}$ y la Disposición Final Primera de la $\mathrm{LPPG}^{51}$

que degradan el paisaje; la mejora paisajística de entornos históricos y arqueológicos y la puesta en valor del paisaje singular de cada lugar como recurso turístico.

${ }^{47}$ Con la creación de esta entidad se pretende responder a las exigencias contenidas en los artículos 7 y 8 del CEP.

${ }^{48}$ En la actualidad, de acuerdo con el artículo 16 del Decreto 316/2009, de 4 junio, por el que se establece la estructura orgánica de la Consellería de Medio Ambiente, Territorio e Infraestructuras, las competencias y funciones de la Administración autonómica en materia de paisaje le corresponden a la Dirección General de Sostenibilidad y Paisaje. Para el ejercicio de estas funciones la Dirección General de Sostenibilidad y Paisaje cuenta con la Subdirección General de Paisaje y Territorio la cual tiene atribuidas, entre otras, las siguientes competencias: a) La protección, gestión y ordenación del paisaje y b) La puesta en marcha de instrumentos para la protección gestión y ordenación de los paisajes de Galicia, tales como los Catálogos del Paisaje de Galicia, las Directrices de Paisaje, los Estudios de Impacto e Integración Paisajística, los Planes de Acción del Paisaje en áreas protegidas, así como cualquier otro que se entienda como necesario para el cumplimiento de los apartados anteriores. Esta Subdirección General de Paisaje y Territorio, a su vez, para el desarrollo de las antedichas funciones dispone del Servicio de Paisaje al que le corresponden las competencias encomendadas a la Subdirección General en lo que concierne al área temática del paisaje y, en general, prestarle asistencia, así como desarrollar cualesquiera otras funciones que, por razón de su competencia, le pueda encomendar la persona titular de la Subdirección General.

49 Tanto en Valencia como en Cataluña existen Organismos similares al Observatorio Gallego del Paisaje. En la Comunidad Valenciana, a través del artículo 65 de la LVOTPP, se creó el Instituto del Paisaje de la Generalitat que se define, de acuerdo con el apartado sexto de dicho precepto, como un órgano de apoyo técnico a la Generalitat y al resto de las Administraciones públicas valencianas en la tarea de definir y ejecutar las políticas de paisaje. En la Comunidad Autónoma de Cataluña, se dispuso la creación del Observatorio del Paisaje, a través de la LCPGOP, cuyo artículo 13.1 lo define como una entidad de apoyo y colaboración con la Administración de la Generalitat en todas las cuestiones relacionadas con la elaboración, aplicación y gestión de las políticas de paisaje.

${ }^{50}$ Este precepto señala: "El Observatorio Gallego del Paisaje adoptará la forma que más se adecue a sus funciones".

${ }^{51}$ Esta Disposición señala: "La Xunta de Galicia, en el plazo de seis meses a contar desde la publicación de la presente Ley, aprobará las disposiciones reglamentarias de desarrollo de [...] la constitución, 
otorgan a la Administración autonómica una amplia discrecionalidad para escoger la forma jurídica que ha de adoptar el mismo, la cual puede ir desde un mero órgano administrativo $^{52}$, hasta un ente personificado, siendo, quizás, los modelos más adecuados a su composición y funciones el de Agencia o el de Consorcio, aunque no se puede descartar el resto de tipos de entes instrumentales previstos por la Legislación autonómica $^{53}$.

Por lo que respecta a su composición, es necesario subrayar que el artículo 13.4 de la LPPG deja en manos de la Xunta de Galicia la determinación de la misma. Si bien esta norma, por una parte, exige expresamente que se garantice la presencia equilibrada de hombre y mujeres, y, por otra parte, dado que lo configura como una entidad de colaboración y coordinación con otras Administraciones y con diversos sectores de la sociedad impone, indirectamente, que dichas Administraciones y sectores sociales se hallen representados en el mismo ${ }^{54}$.

naturaleza jurídica, funciones, composición, funcionamiento y otros aspectos organizativos del Observatorio Gallego del Paisaje [...]”".

52 Tratándose, en este caso, de uno de los órganos previstos en el artículo 22.2 de la Ley 30/1992, de 26 noviembre de Régimen Jurídico de las Administraciones Públicas y del Procedimiento Administrativo Común.

${ }^{53}$ Hay que señalar que el GPPG propuso, a través de su enmienda n. 17, al apartado 2 del artículo 13, que en el texto de la LPPG se estableciese expresamente que el Observatorio no contaría con personalidad jurídica propia. En la Comunidad Valenciana, el artículo 65.2 de la LVOTPP, conforma al Instituto del Paisaje de la Generalidad como una Entidad de Derecho público «con personalidad jurídica pública diferenciada, patrimonio y tesorería propios, así como autonomía de gestión y plena capacidad jurídica y de obrar, correspondiéndole dentro de la esfera de su competencia, el ejercicio de las potestades administrativas precisas para el cumplimiento de sus fines, salvo la potestad expropiatoria». En Cataluña, el artículo 13.2 de la LCPGOP, tampoco determina la forma de personificación jurídica que ha de adoptar el Observatorio del Paisaje. Esta labor se lleva a cabo en el RPC, en cuyo artículo 16.2, se configura como un consorcio adscrito al Departamento de Política Territorial y Obras Públicas.

${ }^{54}$ En esta materia a la hora de proceder al desarrollo reglamentario, como en otras antes apuntadas, se puede tener en cuenta las disposiciones contenidas en la legislación catalana y valenciana. En relación con la composición del Observatorio del Paisaje catalán, hay que señalar que el artículo 13.3 de la LCPGOP, exige que en él cuenten con representación los diversos agentes que actúan sobre el territorio y el paisaje o que están relacionados con el mismo, en concreto, los Departamentos de la Generalitat implicados, los Entes locales y diversos sectores sociales, profesionales y económicos. Además, el artículo 16.3 del RPC añade que formarán parte del Observatorio las Entidades Municipales, los Colegios Profesionales relacionados con la materia, las Universidades catalanas y entidades privadas que lleven a cabo actuaciones relacionadas con el territorio y el paisaje. Hay que destacar que el GPPG propuso, a través de su enmienda n. 17, al apartado 2 del artículo 13, que se estableciese para el Observatorio Gallego del Paisaje una composición similar. Por su parte, el artículo 67 de la LVOTPP dispone respecto de la Organización del Instituto del Paisaje de la Generalitat:

“3. El Consejo Rector estará integrado por el Conseller competente en materia de paisaje, que lo presidirá, por el Director del Instituto del Paisaje de la Generalitat, y por otros miembros que serán designados de la forma que determine el Reglamento de organización y funcionamiento. 
Al Observatorio Gallego del Paisaje, según el artículo 13.4 de la LPPG, le corresponden funciones en seis ámbitos distintos:

1.- Análisis de los paisajes. En este terreno el Observatorio debe evaluar el estado de conservación de los paisajes gallegos y analizar sus transformaciones y previsible evolución.

2.- Estudio e informe en materia paisajística. La actividad del Observatorio Gallego del Paisaje en este ámbito consiste en realizar estudios y propuestas en materia de paisaje y en elaborar cada cuatro años un informe sobre el estado del paisaje en Galicia, informe que la Xunta ha de presentar ante el Parlamento de Galicia.

3.- Planificación en el ámbito paisajístico. En este campo le corresponde al Observatorio delimitar las grandes áreas paisajísticas sobre las que se desarrollarán los Catálogos del Paisaje y elaborar los mismos.

4.- Canalización de la colaboración interadministrativa en materia paisajística. En este ámbito el Observatorio Gallego del Paisaje debe: en primer lugar, promover la colaboración y la cooperación en materia de paisaje, sobre todo mediante la asistencia científica y técnica a otras Administraciones y la realización de intercambios de experiencias con fines de formación e información, especialmente en materia de paisajes transfronterizos; en segundo lugar, actuar como órgano de asesoramiento de las Entidades locales en la implementación de políticas de paisaje en la planificación urbanística y territorial y, en tercer lugar, participar en redes de observatorios de paisaje y entidades semejantes, creadas a nivel estatal, europeo o internacional.

5.- Seguimiento de iniciativas en materia paisajística. Le corresponde al Observatorio hacer el seguimiento de iniciativas de todo tipo, de ámbito estatal, europeo e internacional, en materia de paisaje; en particular de iniciativas de investigación y difusión de conocimientos.

6.- Formación y sensibilización en materia paisajística. Es una función esencial del Observatorio Gallego del Paisaje formar, sensibilizar y concienciar a la sociedad gallega

4. A propuesta del Director del Instituto del Paisaje, el Consejo Rector creará órganos adecuados para fomentar la participación de las instituciones y entidades valencianas relacionadas con las políticas del paisaje, y en particular de las corporaciones locales. Asimismo, se podrán crear órganos adicionales de carácter técnico para realizar tareas de asesoramiento". 
en la necesidad de proteger y gestionar debidamente los paisajes de la Comunidad autónoma.

B. Acciones de formación, sensibilización, educación y concertación

Las Acciones de formación, sensibilización, educación y concertación son, de conformidad con el artículo 14 de la LPPG, aquellas acciones promovidas por la Xunta de Galicia y dirigidas a la sociedad gallega, en general, y a los gestores y usuarios del territorio, en particular, que tienen como finalidad la promoción del entendimiento, respeto y salvaguarda de los elementos que configuran los paisajes de la Comunidad Autónoma.

La LPPG, por una parte, en el campo de la formación y educación, obliga a la Xunta de Galicia a incorporar el estudio del paisaje en los distintos ciclos educativos y a promover la formación de especialistas en intervención del paisaje y, por otra parte, en el ámbito de la concertación, impone a la Xunta el deber de impulsar la celebración de Pactos por el paisaje y de favorecer la realización de Acuerdos voluntarios en las Áreas de Especial Interés Paisajístico.

\section{REFLEXIONES FINALES}

Como se ha puesto de relieve a lo largo del presente trabajo, la LPPG supone un importante avance en la ordenación, gestión, fomento y tutela de los paisajes de la Comunidad autónoma gallega. Sus disposiciones, claramente influidas por la normativa catalana precedente, constituyen el primer paso para dar el debido cumplimiento al CEP.

No obstante, el trabajo que resta por hacer en este campo es mucho todavía. Por ello, sería conveniente que, sin mayor dilación, se procediese a dictar un Reglamento de desarrollo de esta norma en el que se precisasen diversas cuestiones procedimentales para garantizar la operatividad de la LPPG y, acto seguido, se procediese a la constitución del Observatorio del Paisaje y a la elaboración de los instrumentos 
esenciales previstos en la LPPG ${ }^{55}$.

En particular, dentro del citado desarrollo reglamentario, sería conveniente la previsión de un instrumento financiero que tuviese por objeto fomentar la realización de actuaciones paisajísticas con las que se persiga la preservación, recuperación, mejora y promoción de los diferentes paisajes de la Comunidad Autónoma gallega ${ }^{56}$. Es evidente que, sin un adecuado apoyo financiero, muchas de las previsiones de la LPPG corren un serio riesgo de no llegar a actuarse. Quizás, si para la constitución del Observatorio Gallego del Paisaje, se opta por una fórmula orgánica de colaboración entre las Administraciones públicas competentes en la que se dé participación a los demás operadores implicados en este ámbito, como puede ser una Agencia o un Consorcio, este instrumento financiero podría ser un fondo gestionado por dicho Observatorio, el cual podría nutrirse de aportaciones realizadas por la Xunta de Galicia, por las demás Administraciones públicas participantes y por las Entidades privadas vinculadas.

\section{BIBLIOGRAFÍA}

CAAMAÑO DOMÍNGUEZ, F., "Sí, pueden (Declaraciones de derechos y Estatutos de Autonomía)", Revista Española de Derecho Constitucional, núm. 79, 2007.

CANALES PINACHO, F. y OCHOA GÓMEZ, P., "La juridificación del paisaje o de cómo convertir un criterio esencialmente estético en un bien jurídico objetivable", Diario La Ley, núm. 7183, 2009.

DÍAZ OTERO, A., "El valor jurídico del paisaje en el derecho público gallego", Corts: Anuario de Derecho Parlamentario, núm. 21, 2009.

DÍEZ-PICAZO, L., “¿Pueden los Estatutos de Autonomía declarar derechos, deberes y principios?”, Revista Española de Derecho Constitucional, núm. 78, 2007.

— "De nuevo sobre las declaraciones estatuarias de derechos: respuesta a Francisco Caamaño", Revista Española de Derecho Constitucional, núm. 81, 2007.

\footnotetext{
55 La Consellería competente en materia de medio ambiente ha iniciado en los últimos meses la elaboración de los 20 Catálogos del Paisaje previstos. Este órgano ha fijado el año 2014 como fecha para su finalización. Sobre la posible eficacia de estos instrumentos desde la experiencia catalana, vid. NOGUÉ, J. y SALA, P., "El paisaje en la ordenación del territorio. Los catálogos de paisaje de Cataluña", Cuadernos Geográficos, núm. 43, 2008, pp. 69-98.

${ }^{56}$ Este fondo se halla previsto en la LCPGOP y en el RCP, habiendo sido propuesta su incorporación a la LPPG, durante su tramitación parlamentaria, por el GPPG.
} 
EXPÓSITO, E., “La regulación de los Derechos en los nuevos Estatutos de autonomía”, Revista de Estudis Autonòmics i Federals, núm. 5, 2007.

FABEIRO MOSQUERA, A., "La protección del paisaje: su creciente importancia en el ámbito internacional y la dispersión de instrumentos jurídicos para su protección integral en el Derecho español", Revista Española de Derecho Administrativo, núm. $131,2006$.

FERNÁNDEZ RODRÍGUEZ, C., La protección del paisaje. Un estudio de Derecho español y comparado, Marcial Pons, Madrid-Barcelona, 2007.

— "El estreno de nuestro Derecho en la ordenación paisajística: a propósito de la ordenación y protección del paisaje en la legislación valenciana”, Revista de Administración Pública, núm. 172, 2007.

LASAGABASTER HERRARTE, I. y LAZCANO BROTÓNS, I., "Protección del paisaje, ordenación del territorio y espacios naturales protegidos", Revista Vasca de Administración Pública, núm. 70, 2004.

MARTÍN-RETORTILLO BAQUER, L., "Problemas jurídicos de la tutela del paisaje", Revista de Administración Pública, núm. 71, 1973.

MARTÍNEZ LÓPEZ-MUÑIZ, J. L., "Estatutos de Autonomía y Declaraciones de Derechos", Derechos Fundamentales y otros estudios en homenaje al prof. Dr. Lorenzo Martín-Retortillo, vol. I, Gobierno de Aragón et al., Zaragoza, 2008.

MARTÍNEZ MARTÍNEZ, E., "La Ley 4/2004, de ordenación del territorio y protección del paisaje de la Comunidad Valenciana: hacia una ordenación estructural sostenible", Revista Aranzadi de Derecho Ambiental, núm. 9, 2006.

- La protección del medio natural en la Ley 4/2004, de ordenación del territorio y protección del paisaje de la Comunidad Valenciana, Corts Valencianes, Valencia, 2007.

MARTÍNEZ NIETO, A., "La protección del paisaje en el Derecho español”, Revista de Derecho Ambiental, núm. 10, 1993.

— "La protección del paisaje en el Derecho español (I)", Actualidad Administrativa, núm. 32, 1993. 
— "La protección del paisaje en el Derecho español (II), en Actualidad Administrativa, núm. 33, 1993.

— "La contaminación del paisaje”, Actualidad Administrativa, núm. 20, 1998.

NOGUÉ, J. y SALA, P., "El paisaje en la ordenación del territorio. Los catálogos de paisaje de Cataluña", Cuadernos Geográficos, núm. 43, 2008.

NOGUEIRA LÓPEZ, A., "La regulación medioambiental en la Comunidad Autónoma de Galicia (Ley de Protección Ambiental de Galicia y decretos de desarrollo)", Revista Andaluza de Administración Pública, núm. 24, 1995.

— "La actividad de fomento para la protección de la atmósfera", en prensa.

NOGUEIRA LÓPEZ, A., SANZ LARRUGA, F. J., “Galicia: los afanes por aprobar las leyes y planes ambientales pendientes en el final de la legislatura”, en López Ramón, F. (coord.), Observatorio de políticas ambientales 2009, Thomson Reuters, Cizur Menor, 2009 .

ORTEGA ÁlVAREZ, L., "Los derechos ciudadanos en los nuevos estatutos de autonomía", Derechos Fundamentales y otros estudios en homenaje al prof. Dr. Lorenzo Martín-Retortillo, vol. I, Gobierno de Aragón et al., Zaragoza, 2008.

PRIEUR, M., "La Convención Europea del Paisaje”, Revista Andaluza de Administración Pública, núm. 50, 2003.

DE VICENTE GONZÁLEZ, J. L. "Normas de aplicación directa y protección del paisaje en la Ley de Cantabria 2/2001, de 25 de junio. ¿Límites a la discrecionalidad de la Administración o conceptos jurídicos indeterminados?", Revista de Estudios de la Administración Local, núm. 292-293, 2003.

ZOIDO NARANJO, F., "La Convención Europea del Paisaje y su aplicación en España”, Ciudad y Territorio. Estudios Territoriales, núm. 23 (128), 2001. 